DEPARTMENT OF COMMERCE

BUREAU OF STANDARDS

George K. Burgess, Director

CIRCULAR OF THE BUREAU OF STANDARDS, No. 149

\title{
A STANDARDIZED METHOD OF \\ MEASURING THE SIZE OF HOSIERY
}

FEBRUARY 1, 1924.

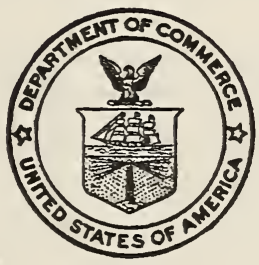

PRICE, 5 CENTS

Sold only by the Superintendent of Documents, Government Printing Office Washington, D. C.

WASHINGTON

GOVERNMENT PRINTING OFFICE 


\section{A STANDARDIZED METHOD OF MEASURING THE SIZE OF HOSIERY.}

ABSTRACT.

As a result of cooperation of the National Association of Hosiery and Underwear Manufacturers, methods of measuring the size of hosiery were investigated, and a standard method based on the suggestions of the Bureau of Standards was selected by a committee of manufacturers. Inquiries to a number of manufacturers and users brought out the fact that no large class of them used the same method of measuring. This resulted in a great confusion of marked sizes on hosiery. The standard method described in this paper has been adopted by the manufacturers, and the Government departments through the Federal Specifications Board, and is being introduced to the retailers and consumers.

The lack of standardization in the textile industry is forcibly evidenced by the failure of the hosiery interests to observe the advantages to be obtained by developing and adopting universally some standard method for measuring hosiery. A consumer using one particular size of hosiery from one manufacturer changing to the same marked size of a different brand might be subjected to discomfort resulting from misfitted hosiery, because of the difference in actual size resulting from a difference in method of measuring. The wearing qualities of the material will probably be affected, for if the hosiery is too small, the pressure of the foot combined with abrasion will cause frequent ruptures at the toe or heel.

This apparent lack of a standard method of measuring the size of hosiery or of a definition of what is meant by the size of hosiery caused the National Association of Hosiery and Underwear Manufacturers to send out a number of questionnaires to some of the largest manufacturers in order to ascertain the existing methods of measuring. It was the intent of that association to develop a standard nomenclature of size in order to obviate the uncertainty that exists in the designation of hosiery sizes. This association asked the cooperation of the Bureau of Standards, the latter serving in this development in studying and analyzing the different methods found and suggesting one method which could be considered for adoption by the manufacturers' committee.

The "size of hosiery" is an accepted trade term, and for circular knit hosiery is the measured distance in inches between two $72836^{\circ}-24$ 
points of the toe and heel, measured in a straight line. The differences in practice, however, resulted from nonuniformity of the position of this line in connecting the toe and the heel.

In attempting to find the various methods of measuring now employed, the following questionnaire was sent out by J. N.

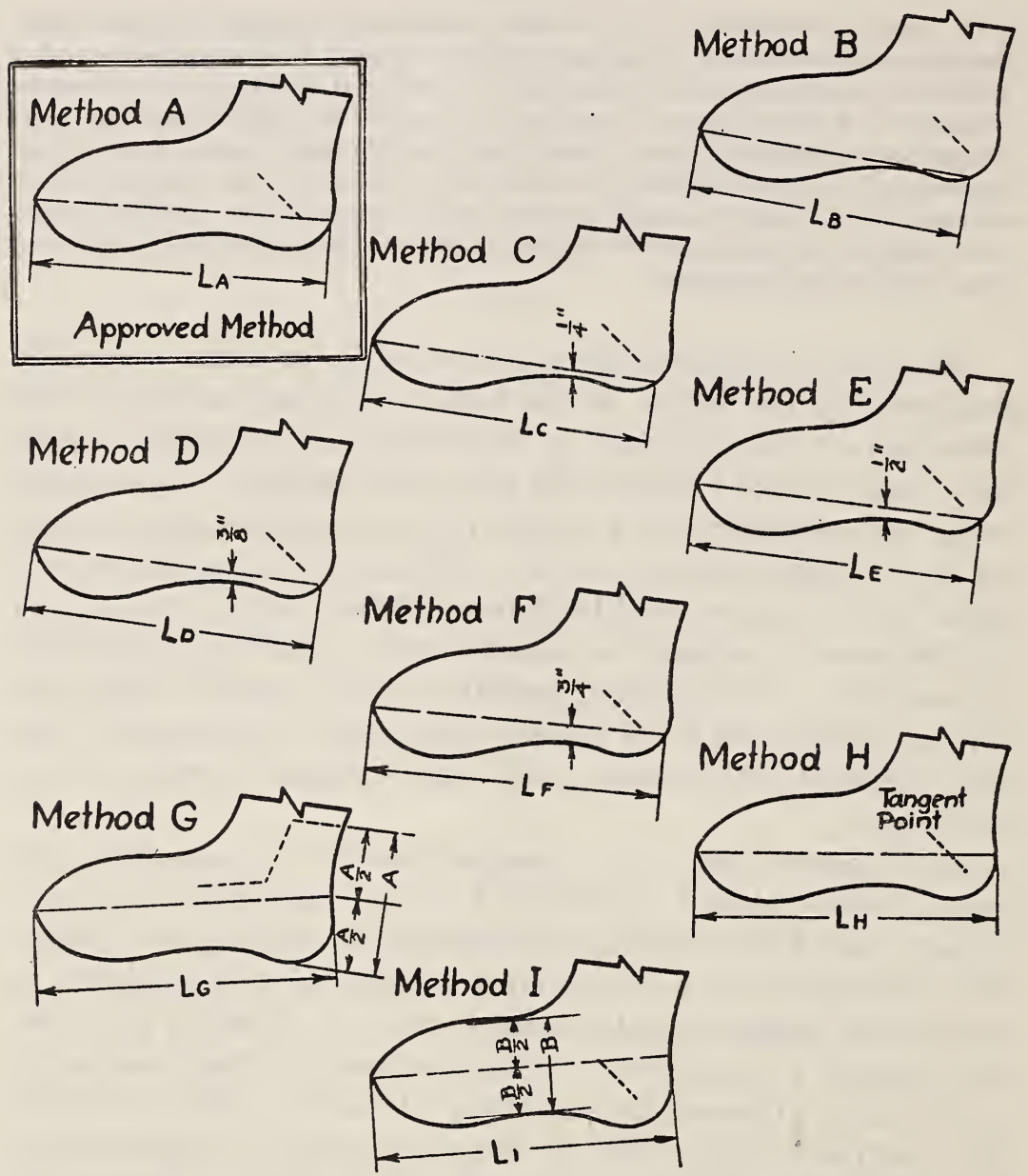

FIG. I.-Methods used in measuring the size of hosiery by nine different manufacturers.

Mrethod A is now the approved practice.

McCullaugh, national secretary and consulting industrial manager of the association.

This office has started to work with the Bureau of Standards on subjects of research and standardization in Washington. There is no doubt that there are many things existing in this industry, as well as in all others, that are the result of practice rather than careful thought and attention. We are all more or less prone to accept industrial 
inheritances, without profound investigation, if these inheritances can be classified as "trade practice." The writer has had occasion to question several manufacturers as to the method of measuring hosiery. He has found at the present time that there are four different standards used by the various manufacturers to measure the size of a foot. It seems to me that this is one of the primary conditions that should be corrected through your association; that is, let us arrive at a standard method of measuring, and from there we can build up, I believe, into many things.

Will you please send to this office at your earliest possible convenience your standard method of measuring, in order that we may make a comparison and form deductions from it.

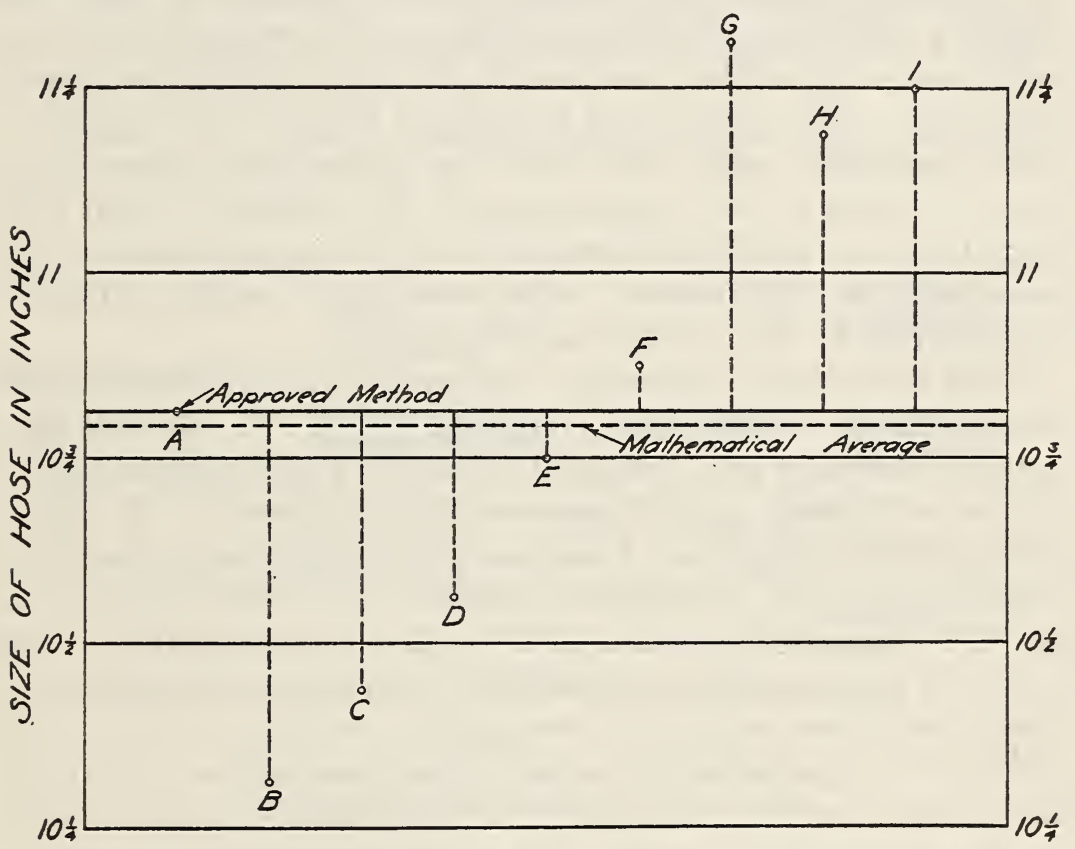

FIG. 2.-Variation from approved method $A$ in the results from eight other existing methods of measuring one selected specimen of hosiery.

From the replies received it was found that nine different systems of measuring circular knit hosiery were in use. Figure I shows methods $\mathrm{A}$ to $\mathrm{H}$, inclusive, each varying in the resultant length of line drawn from tip of toe to a point along the back of the heel, when the stocking is laid in a flat position. In applying these different systems to a single selected hose, measurements were made and found to vary more than $I$ inch. One inch difference in length is interpreted as one size difference.

From Figure 2, in which the resultant length of hose produced by each method is plotted vertically over the different systems, a variation between measurement and marked size was found of I $\frac{5}{16}$ to a minimum of $10 \frac{5}{16}$. This could be interpreted as mean- 
ing that for one particular hose one manufacturer would perhaps label it size IO, another size II, and still another IO $1 / 2$. The lengths of hose were measured to the nearest one-sixteenth of an inch. Accordingly, it will be found that the lengths of stocking do not fall exactly on the standard sizes manufactured. For men's hosiery, these standard sizes are $91 / 2$, IO, IO $1 / 2$, I I, II I 12 , and 12 ; for women's hosiery, $8,81 / 2,9,91 / 2,10$, and 10 $1 / 2$. With the existing practices it is possible that by systems $B$ and $C$ of Figure 2 hosiery would be called size Io; by methods D, E, A, and $F$, size $101 / 2$; while by methods $G, H$, and $I$, it would be classed as size II. This, however, is not always true, as some manufacturers purposely make what would be termed and measured a size IO $1 / 2$ - that is, IO $1 / 2$ inches long by, say, method A-but still mark the goods size ro for the purpose of giving extra length and accordingly, as they believe, extra service and comfort. This is an exception to the general marking practice.

After this survey was made, the report was rendered to the manufacturers' committee, composed of J. N. McCullaugh, national secretary and industrial manager of the National Association of Hosiery and Underwear Manufacturers; J. H. Zens, president of the National Association of Hosiery and Underwear Manufacturers; W. W. Moyer, president of W. W. Moyer Co.; and S. D. Bauscher, president of S. D. Bauscher \& Son (Inc.). As a result of their consideration, method $\mathrm{A}$ was approved as standard. This selection was made from two points of reasoning: First, that method $\mathrm{A}$ is approximately equal to the numerical average of all nine systems; that is, the average of the dimensions of all systems on the same hose; second, from a consideration of the most consistent points in the foot of the hosiery in respect to its manufacturing construction. This latter point involved a consideration of the points which are included in the different shapes of hosiery forms and of the practices which are employed in the constructions of the heel and toe, including the ratio of needles dropped and needles employed in constructing the heel and toe, and also including the length of the gore in terms of the number of stitches. This necessitates that the heel gore be always a certain proportionate distance from the curve of the heel toward the bottom of the foot. In boarding the stocking, care is taken to have the gores run parallel to each other. These two points were found to be the tip of the toe and the lower part of the heel gore. These points were decided upon by consensus of opinion of several experts and the committee. 
The method of measuring the size of circular knit hosiery by method A may be defined as follows: After the hose has been boarded and pressed and appears in a flat and unwrinkled condition, place a ruler along a line in which the tip of the toe and the bottom of the heel gore are connected. The measured distance along this line from tip of toe to the intersection with the back of the heel to the nearest half inch is the hosiery size. Preference should be given to the lower number; that is, if the exact measurement, as found by the system, is ro $1 / 4$ inches exactly, it is desirable to call the stocking size ro.

Figure 3 is a diagram showing application of ruler between the points selected denoting size.

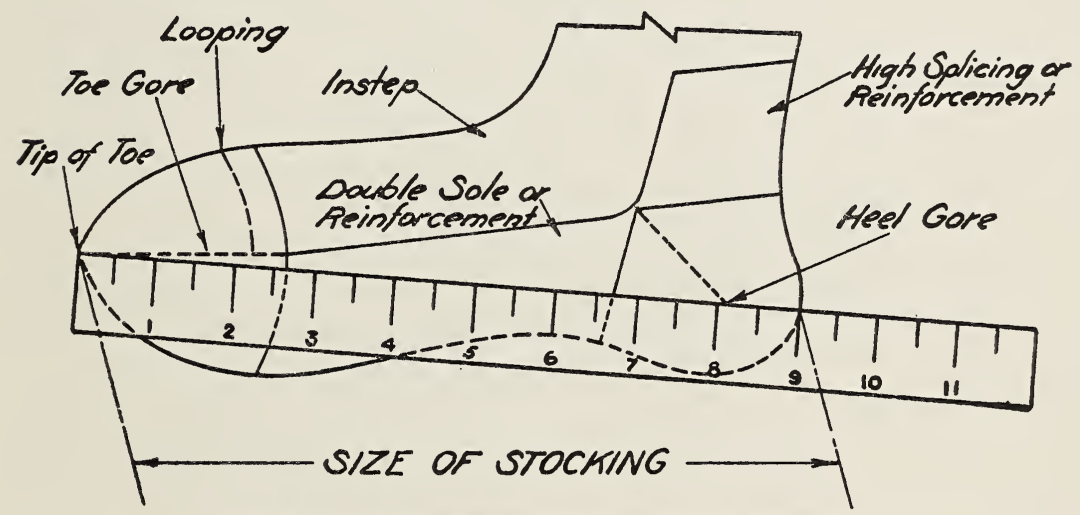

Fig. 3.-Approved method for measuring hosiery.

This diagram shows the application of ruler to the hosiery.

The development of a standard method of measuring hosiery, as described in this circular, is the first attempt known to the writers to standardize the method of measurement. It has resulted in a general adoption, and having been introduced about six months ago is very widely used to-day. The following associations have adopted this standard method: The National Association of Hosiery and Underwear Manufacturers, comprising a very large per cent of the hosiery manufacturers; the Federal Specification Board, representing the Government, one of the largest users of textiles; the American Home Economics Association, who will be very valuable in familiarizing the public with this method of measurement; and the Bureau of Standards, which has recorded this standard as a trade practice. 

